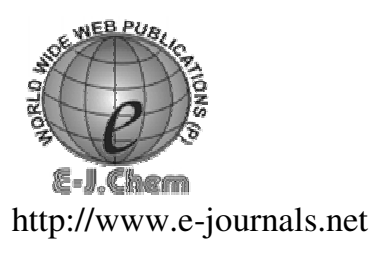

ISSN: 0973-4945; CODEN ECJHAO

E-Journal of Chemistry

Vol. 5, No.2, pp. 365-369, April 2008

\title{
Mild and Efficient Oxidation of Aromatic Alcohols and Other Substrates Using $\mathrm{NiO}_{2} / \mathrm{CH}_{3} \mathrm{COOH}$ System
}

\author{
MOHAMMAD KOOTI* and MEHDI JORFI \\ Department of Chemistry, College of Science, \\ Shahid Chamran University, Ahvaz, Iran \\ m_kooti@scu.ac.ir
}

Received 8 October 2007; Accepted 16 November 2007

\begin{abstract}
A variety of aromatic alcohols were efficiently oxidized to their corresponding aldehydes and ketones in good to excellent yields using nickel peroxide activated by acetic acid. Some thiols and amines were also readily oxidized by this oxidant under mild conditions.
\end{abstract}

Keywords: Oxidation, Nickel peroxide, Alcohols, Catalyst.

\section{Introduction}

The oxides and oxyanions of vanadium, chromium, manganese ${ }^{1}$ and even iron $^{2}$ have proven to be useful oxidants. These oxides and some of the heavy metal oxides ${ }^{3,4}$ have been widely used in oxidation of organic substrates. However, there are a number of drawbacks against the classical oxidants $\left(\mathrm{CrO}_{4}{ }^{2-}, \mathrm{MnO}_{4}{ }^{-}\right)$and their use in organic synthesis. These include lack of selectivity, the requirement of a strong acid or base as catalyst and above all their high toxicity for man and environment ${ }^{5}$. Therefore, the development of efficient and less polluting oxidants is highly encouraged.

The powerful common oxidants are mostly derived from metals located around the middle of the first transition series. In contrast, the metals at the end of the first transition series are not capable of forming high-valent oxides and thus remain less studied. However, among these metals, nickel can readily form peroxide $\left(\mathrm{NiO}_{2}\right)$ which was used for oxidation of several substrates ${ }^{6}$. One of the first groups to study nickel peroxide pointed out that it is not a reliable oxidant for aliphatic alcohols in organic solvents ${ }^{6}$. This group has also reported that aromatic alcohols can be only converted to their carbonyl compounds by nickel peroxide with good yields under heating conditions in benzene. George et al. ${ }^{7}$ have also studied the oxidation of some organic compounds using nickel peroxide in benzene but the reported results were not satisfactory. In 1974, George and Balachandran published an excellent review covering most of the research which was carried out using nickel peroxide as oxidant ${ }^{8}$. Since then, only sporadic reports have appeared in the literature dealing with oxidation of various organic substrates by nickel peroxide ${ }^{9-12}$. 
We have, therefore, investigated the oxidation of various organic substrates by nickel peroxide in the presence of different materials as promoters to find out a suitable activator for this oxidant. We have observed that the oxidation of a series of alcohols to aldehydes and ketones, oxidative coupling of thiols to disulfides and oxidation of some amines proceed rapidly and efficiently by nickel peroxide in the presence of acetic acid.

\section{Experimental}

\section{Preparation of nickel peroxide}

A solution of $\mathrm{KOH}(22.4 \mathrm{~g})$ in $100 \mathrm{~mL}$ of water was chilled and chlorine gas (generated from $20 \mathrm{~g}$ of $\mathrm{KMnO}_{4}$ and $120 \mathrm{~mL}$ of concentrated $\mathrm{HCl}$ ) was slowly bubbled over for one hour period with stirring. To the resulting yellow solution of $\mathrm{KClO}$, was added $11.63 \mathrm{~g}(0.04$ mol) of $\mathrm{Ni}\left(\mathrm{NO}_{3}\right)_{2} \cdot 6 \mathrm{H}_{2} \mathrm{O}$ portion-wise in $20 \mathrm{~min}$ while stirred in an ice bath. A fine black precipitate formed which was filtered and washed with deionized water and dried at $110{ }^{\circ} \mathrm{C}$ for $3 \mathrm{~h}$ to afford $3.42 \mathrm{~g}$ of $\mathrm{NiO}_{2}(95 \%$ yield $)$.

\section{Oxidation of organic substrates}

To a solution of $1.0 \mathrm{mmol}$ of an organic substrate and $1.0 \mathrm{mmol}$ of acetic acid in $15 \mathrm{~mL}$ of $n$-hexane, $4 \mathrm{mmol}$ of nickel peroxide was added while stirred magnetically. The suspension was allowed to react and the reaction was monitored by TLC. After a desired time the reaction was stopped, the heterogeneous solution was filtered and the spent $\mathrm{NiO}_{2}$ was washed with $\mathrm{CH}_{2} \mathrm{Cl}_{2}$. After removing of the solvent the product was isolated and characterized by comparing its spectroscopic data with an authentic sample.

\section{Recovery of nickel peroxide}

The spent nickel peroxide was first washed with acetone and then with water to remove the adhered organic compounds and often impurities. The solid was then stirred with $\mathrm{KClO}$ solution (about ten times the quantity of $\mathrm{NiO}_{2}$ ) for $30 \mathrm{~min}$. The recovered $\mathrm{NiO}_{2}$ was filtered, washed with water and kept dried for new oxidation process.

\section{Results and Discussion}

We have used the method introduced by Nakagawa et al. ${ }^{6}$ with some modification for the preparation of nickel peroxide. All the oxidation reactions, except some experiments, were carried out in n-hexane at room temperature.

To start our investigations on the oxidation of organic substrates with nickel peroxide, we have selected 1-phenyl ethanol as a probe substrate. Thus, 1-phenyl ethanol (1.0 mmol) and nickel peroxide $(4.0 \mathrm{mmol})$ were suspended in $n$-hexane $(15 \mathrm{~mL})$ together with acetic acid $(1.0 \mathrm{mmol})$ as catalyst. The suspension was stirred for a desired time and the reaction was monitored by TLC. The products were then isolated and characterized by comparison of their spectroscopic data with those reported in the literature. The results are gathered in Table 1, for various materials as catalyst. The stochiometric oxidation is expressed as follows (Scheme 1).

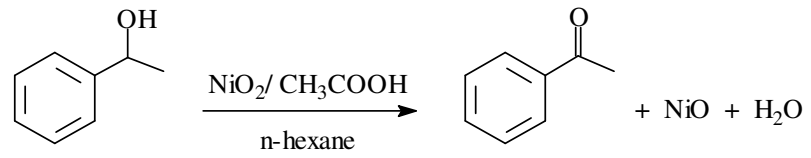

\section{Scheme 1}


Table 1. Oxidation of 1-phenyl ethanol to acetophenone by $\mathrm{NiO}_{2}$ in the presence of different catalysts.

\begin{tabular}{cccc}
\hline Entry & Catalyst & Time, $\mathrm{h}$ & Yield, \% \\
\hline 1 & $\mathrm{Non}$ & 5 & 50 \\
2 & $\mathrm{Al}_{2} \mathrm{O}_{3}$ & 6 & 45 \\
3 & $\mathrm{CuSO}_{4} .5 \mathrm{H}_{2} \mathrm{O}$ & 3 & 37 \\
4 & $\mathrm{Silica}_{\mathrm{al}}$ & 2.5 & 55 \\
5 & $\mathrm{CH}_{3} \mathrm{COOH}$ & 1.5 & 88 \\
6 & $\mathrm{CF}_{3} \mathrm{COOH}$ & 3.5 & 36 \\
7 & $\mathrm{Al}_{2} \mathrm{O}_{3}, \mathrm{CH}_{3} \mathrm{COOH}$ & 3 & 34 \\
8 & $\mathrm{Al}_{2} \mathrm{O}_{3}, \mathrm{CF}_{3} \mathrm{COOH}$ & 4 & 25 \\
9 & $\mathrm{H}_{2} \mathrm{O}$ & 3 & 43 \\
10 & $\mathrm{Al}_{2} \mathrm{O}_{3}, \mathrm{H}_{2} \mathrm{O}$ & 4 & 40 \\
11 & $\mathrm{AlCl}_{3}$ & 2.5 & 59 \\
12 & $\mathrm{CH}_{3} \mathrm{COOH}$ & $3^{\mathrm{a}}$ & 65 \\
13 & $\mathrm{CH}_{3} \mathrm{COOH}_{2}$ heat $60{ }^{\circ} \mathrm{C}$ & 1.5 & 30 \\
\hline
\end{tabular}

${ }^{a}$ The reaction was carried out with molar ratio $1: 3$ of alcohol : oxidant respectively

As it is seen, the best result is obtained by nickel peroxide/acetic acid combination (entry 5). It is interesting to note that some of the tested materials, such as alumina, $\mathrm{CuSO}_{4} .5 \mathrm{H}_{2} \mathrm{O}$ and silica gel (entries 2-4) which showed activating effect on the oxidation of alcohols by other oxidants ${ }^{13,14}$, did not affect nickel peroxide oxidizing power in our study. Nickel peroxide in the absence of any catalyst gives only $50 \%$ yield of acetophenone even after $5 \mathrm{~h}$ of reaction time (entry 1). This sluggish reaction might be due to high insolubility of $\mathrm{NiO}_{2}$ in n-hexane. The obtained yields of acetophenone using other substances as catalyst such as stronger acid $\left(\mathrm{CF}_{3} \mathrm{COOH}\right)$, combination of acids with alumina, trace of moisture, wet alumina or $\mathrm{AlCl}_{3}$ (entries 6-11) were all rather poor. Moreover, performing the oxidation of 1-phenyl ethanol with $\mathrm{NiO}_{2}$ in the presence of $\mathrm{CH}_{3} \mathrm{COOH}$ at $60{ }^{\circ} \mathrm{C}$ did not bring about any improvement in the yield (entry 13). A control experiment using less amount of oxidant, 1:3 alcohol:oxidant instead of 1:4 molar ratio was also carried out. The result however was not satisfactory and only $65 \%$ yield of acetophenone was obtained (entry 12) compared with $88 \%$ yield of 1:4 molar ratio.

As acetic acid seemed to be the best catalyst among the tested materials in activating nickel peroxide, we have studied the oxidation of various alcohols, two amines and two thiols by our oxidation system. In all experiments, we have used a molar ratio of 1:4:1 of substrate, nickel peroxide and acetic acid respectively. Benzylic, substituted benzylic and allylic alcohols are readily converted to their corresponding carbonyl derivatives when treated with $\mathrm{NiO}_{2}$ in the presence of acetic acid in n-hexane. As shown in Table 2, except a few cases, all of the examined aromatic alcohols give excellent yields of aldehydes or ketones in less than $3 \mathrm{~h}$ reaction time. Moreover, the primary alcohols were not further oxidized to carboxylic acids which reveal the relative mildness of our oxidation system.

In addition to alcohols, we have also examined the oxidation of two amines and two thiols to check the efficiency of our oxidant. Thus, treating of $n$-hexane solution of aniline or benzyl amine with nickel peroxide in the presence of acetic acid afforded the corresponding diazo and nitrile compound respectively in good yields (entries 13,14), (Table 2). Similarly, reacting of thiophenol and $p$-methyl thiophenol with nickel peroxide/acetic acid in $n$-hexane gives rise to the production of the corresponding symmetrical disulfide products, resulting from oxidative coupling, with excellent yields (Table 2). 
Table 2. Oxidation of some organic compounds with $\mathrm{NiO}_{2}$ in $n$ - hexane (unless otherwise mentioned)

(2)

${ }^{a}$ Isolated yields. Spectrocopic analysis of the isolated compounds $\left(I R,{ }^{1} H\right.$ and $\left.{ }^{13} C N M R\right)$ was in concordance with those reported in the literature. ${ }^{b}$ The reaction was carried out in ether.

${ }^{C}$ The reaction was carried out in $\mathrm{CH}_{2} \mathrm{Cl}_{2}$ 
In view of the obtained results, our oxidation system seemed to be a facile and efficient means for oxidation of various organic substrates. The yields and the reaction conditions are much superior to those previously reported ${ }^{7,11}$. We have replaced the less polluting n-hexane solvent with the highly polluting benzene used by previous researchers ${ }^{6-8}$. There was no sign of over-oxidation of the alcohol in our system as it usually occurred with other oxidants ${ }^{15}$. Other advantages of worthwhile mentioning about our oxidation system are that both nickel peroxide and acetic acid are inexpensive and relatively environmentally benign materials. In addition, the spent nickel peroxide can be easily recovered and reused in oxidation of organic substrates, which is of particular interest to chemists.

\section{Acknowledgements}

We are pleased to acknowledge the partial financial support for this study by the Research Council of Shahid Chamran University, Ahvaz, Iran.

\section{References}

1. (a) Hudlicky, M. Oxidation in organic chemistry; ACS Monographs 186: Washington, DC; 1990. (b) Lee D G, The oxidation of organic compound by permanganate ion and hexavalent chromium, Open Court, 1980.

2. Delaud L, Laszlo P and Lahance P, Tetrahedron Lett. 1995, 36, 8505.

3. Yusubov M S, Chi KW, Park J Y, Karimov R and Zhdankin V, Tetrahedron Lett. 2006, 47, 6305.

4. Coats R M, Senter P D and Baker W R, J. Org. Chem. 1982, 47, 3597.

5. Cusumano J A, J.Chem. Educ. 1995, 72, 959.

6. A Nakagawa K, Konaka R and Nakata T, J. Org. Chem. 1962, 27, 1597.

7. Balachandran K S, Bhatnagar I and George M V, J. Org. Chem. 1968, 33, 3891.

8. George M V and Balachandran K S, Chem. Rev. 1974, 75, 491.

9. Kim K S, Cho S B and Hahn C S, Bull. Korean Chem. Soc. 1991, 12, 115.

10. Lai T L, Lee C C, Wu K S, Shu Y Y and Wang C B, Appl. Catal. B: Envirn. 2006, 67, 147.

11. Ji H, Wang T, Zhang M, She Y and Wang L, Appl. Catal. A: General, 2005, 282, 25.

12. Grill J M, Ogle J W and Miller S A, J. Org. Chem. 2006, 71, 9291.

13. Kim K S, Song Y H, Lee N H and Hahn C S, Tetrahedron Lett. 1986, 27, 2875.

14. Merger F M and Lee C, J. Org. Chem. 1979, 44, 3446

15. Bartholomew C H, Farrauto R J, Fundamental of Industrial Catalytic Process; Wiley, Hoboken, NJ, 2006 


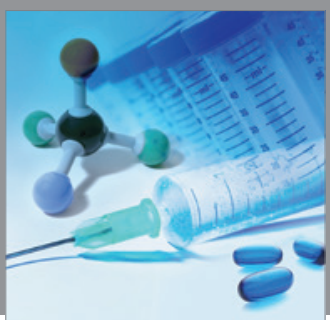

International Journal of

Medicinal Chemistry

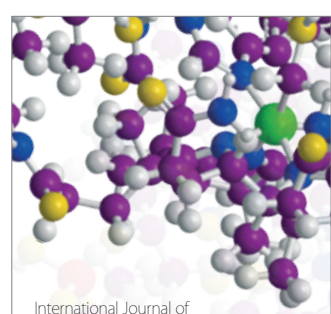

Carbohydrate Chemistry

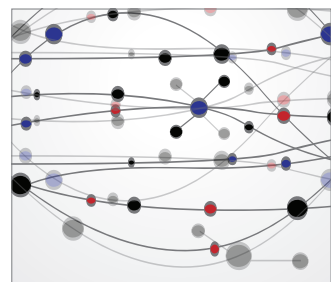

The Scientific World Journal
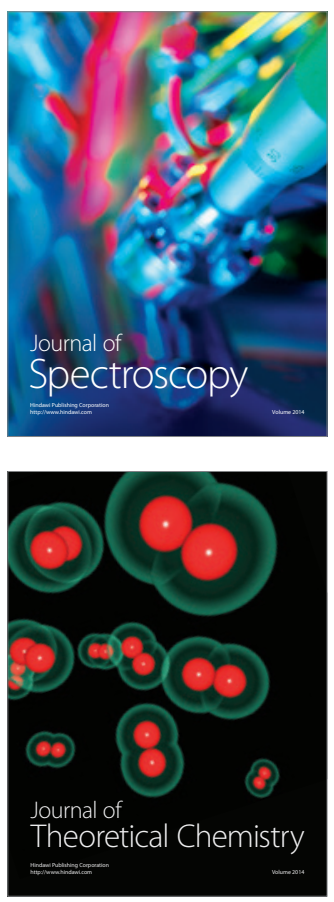
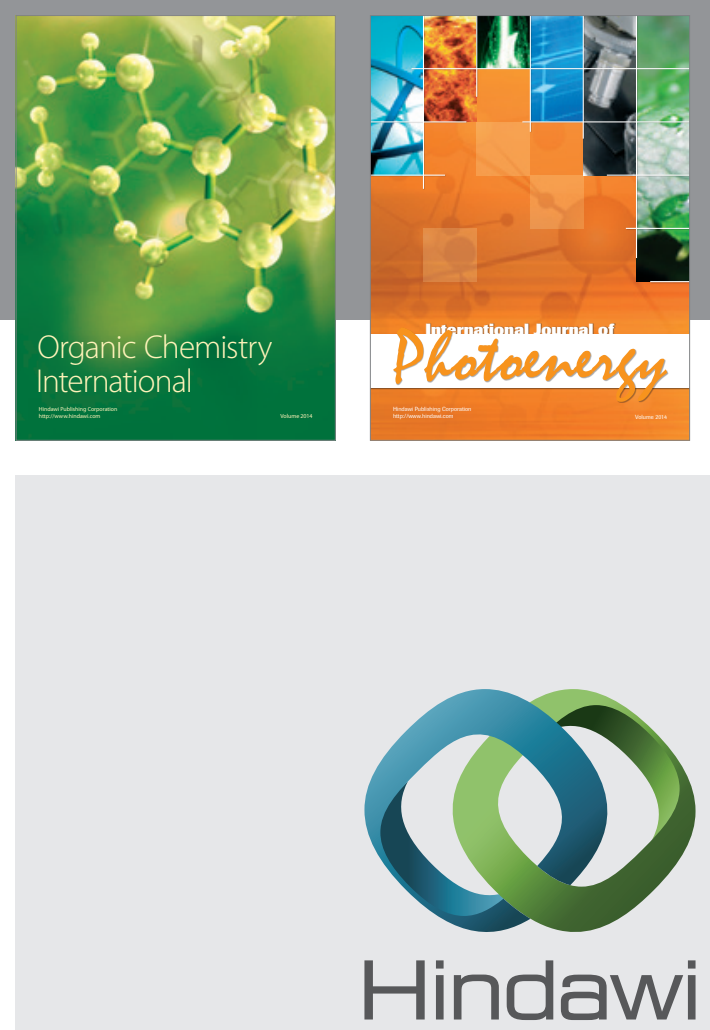

Submit your manuscripts at

http://www.hindawi.com
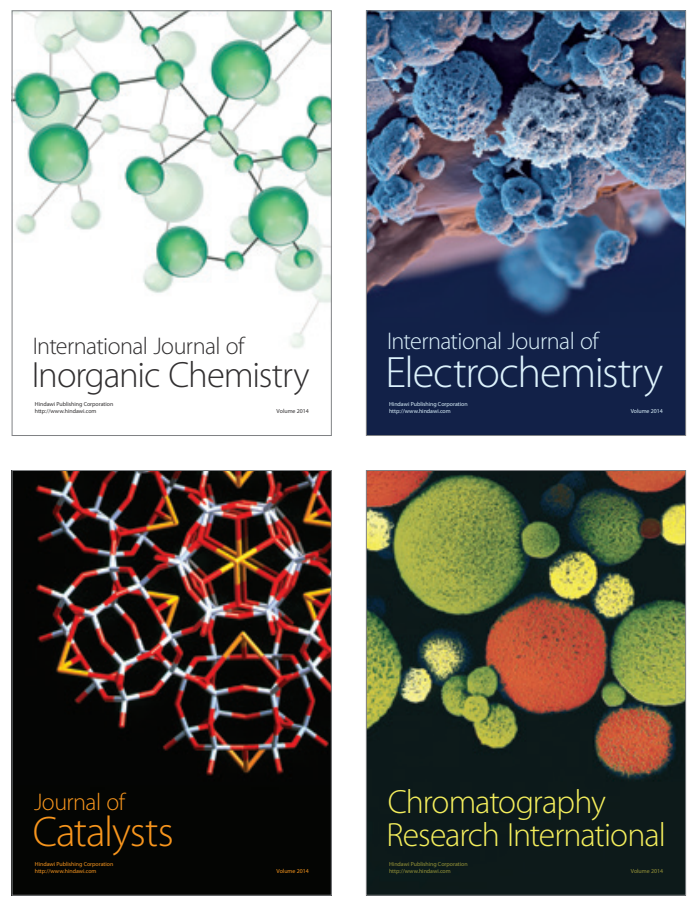
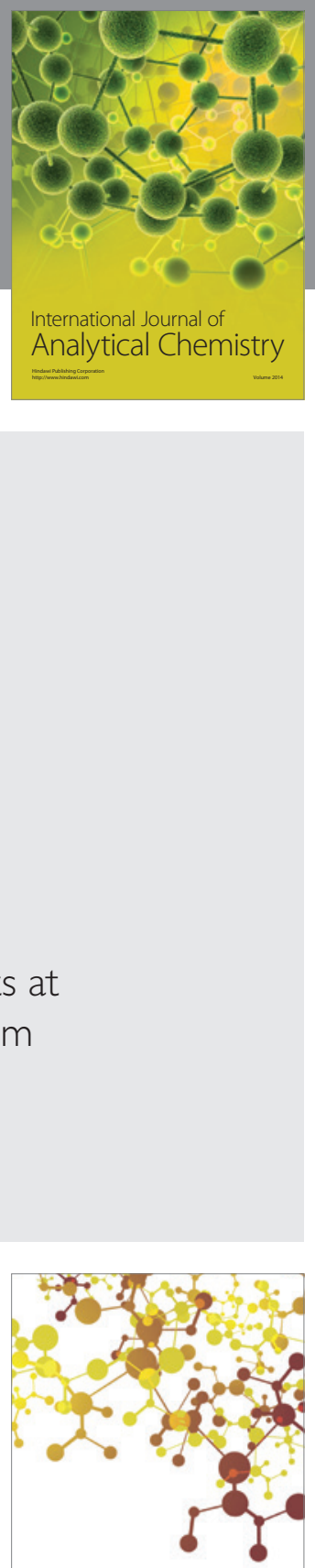

Journal of

Applied Chemistry
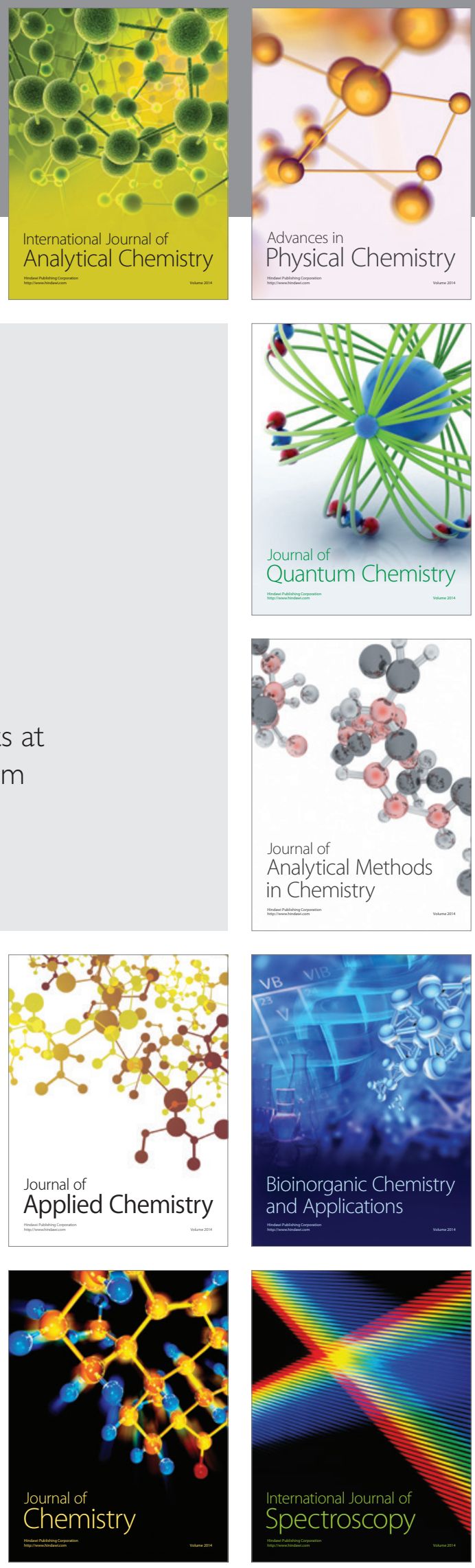